\title{
PLANO DE AÇÃO PARA IMPLANTAÇÃO DE ENSINO À DISTÂNCIA EM UMA INSTITUIÇÃO DE ENSINO SUPERIOR PRIVADA:
}

\author{
Inês Aparecida Ferreira* - UNOPAR \\ Samira Fayez Kfouri* - UNOPAR
}

Palavras-chaves: Gestão. Planejamento. Ensino à Distância.

\section{INTRODUÇÃO}

Um plano de ação implica autoconhecimento. Parte da análise da situação real, seguida das fases de direcionamento, de elaboração de planejamento estratégico e de refinamento, constituindo-se em grande oportunidade para construir, rever ou desenvolver um programa. Observa-se ainda que os planos sejam guias, não mandamentos, devendo ser flexíveis e passiveis de reestruturação.

O planejamento da gestão para o Ensino à distância (EAD) tem a finalidade de organizar, viabilizar e consolidar todos os elementos da implantação do EAD na instituição. Em outra perspectiva, referencia-se como uma ferramenta estratégica, prévia e essencial para o desenvolvimento do EAD.

Para tanto o estudo visa analisar a dinâmica do modelo de gestão e estratégias sendo construído e os paradigmas que estão sendo rompidos historicamente, desde o inicio da implantação do ensino virtual em uma Instituição de Ensino superior (IES) privada, determinados pelas políticas públicas e diretrizes no âmbito do ensino superior.

A escolha do método de pesquisa se deve ao fato de ser idealizada e realizada em estreita associação com uma ação ou com a resolução de um problema coletivo e no qual os pesquisadores e participantes representativos da situação ou do problema estão envolvidos de modo cooperativo ou participativo.

Durante a pesquisa-ação foram realizadas conversas exploratórias,

\footnotetext{
*E-mail: ines.aparecida@gmail.com

*E-mail: samirakfouri@hotmail.com
} 
observações e reuniões técnicas com diretores, coordenadores de cursos, docentes e administrativo, ficando estabelecida a realização do plano de ação para a implantação do EAD na IES, a cargo da coordenação de EAD.

O EAD será tratado como um método educacional na qual os agentes educacional e discente encontrem-se separados pelo tempo ou espaço, empregando para a interação e comunicação as Tecnologias de Informação e Comunicação (TIC's).

A necessidade de construir um modelo de gestão baseado nas especificidades do EAD, justifica o presente estudo, e ainda pelo interesse da autora que no momento exerce a função de gestora de EAD em uma instituição privada.

Espera-se que o referido estudo contribua para a compreensão das suas peculiaridades, destacando a importância do processo de gestão no conjunto de informações que compõem o processo educacional, destacando os desafios que seus gestores notam em face do cotidiano. Que possa servir de guia às instituições no desenvolvimento de ferramentas e processos de gestão da EAD em consequência incentivar a relação entre o modo de trabalho, consolidando o entendimento de uma abordagem profissional de gestão, pressupondo infraestrutura tecnológica, planejamento eficaz, dinâmico e adequado frente às demandas do processo vinculado à EAD.

\section{DESENVOLVIMENTO}

Segundo Luck, (2007, p.15), a gestão educacional é, por conseguinte interesse de profissionais que atuam em gestão escolar (diretores, supervisores, coordenadores e orientadores educacionais), com caráter amplo e abrangente, do sistema de ensino no âmbito macro, a gestão escolar, compõem-se em área estrutural de ação na resolução da dinâmica e da qualidade do ensino. Visto que é pela gestão que se situa unidade, direcionamento e coerência à ação educacional. $A$ gestão é uma área meio e não um fim em si mesmo.

Para que os objetivos da IES sejam alcançados, é necessário estabelecer as forma de ação, que podem ser desenvolvidas por intermédio das estratégias organizacionais. Estas estratégias são guiadas por questões politicas, envolvendo interesses, e funcionam como parâmetros para o estabelecimento de regras, 
normas, valores, e processos preconizados pela IES.

A implantação do EAD iniciou suas atividades na IES em fevereiro de 2012, por meio da Direção e Consultoria, na estruturação legal dos processos.

A Coordenadoria de EAD iniciou com a contratação da coordenadora, a autora do referido relato. Após a contratação da Coordenação EAD em 2013, foi colocado em pratica à implantação dos 20\% EAD para cursos presenciais conforme Portaria MEC 4.059/04. Considerando os quatro semestres foram atendidos mais de 1.000 alunos em três disciplinas.

Para cumprir essa linha mestra, toda a instituição vem passando por ajustes, ordenamentos e realinhamentos para garantir que o objetivo seja alcançado.

O corpo dirigente da IES entende que para atender a demanda de formação profissional e inserção no mundo produtivo e social, o EAD pode proporcionar educação de boa qualidade por meio de gestão e metodologias inovadoras com base nas ferramentas de Tecnologias de Informação e Comunicação - TIC. Na pratica profissional, pode-se observar que para implementar as políticas definidas para o EAD, a IES necessitava estabelecer um cronograma de ações que atende, preferencialmente, o treinamento do corpo docente e dos técnico-administrativos. Além disso, foi também estabelecida como prioridade criar regimentalmente uma Coordenadoria de Educação a Distância e o Núcleo de Integração Pedagógica para produção de material didático e apoio aos docentes na preparação das aulas. $\mathrm{Na}$ Secretaria Acadêmica foi criada a Secretaria Setorial de EAD e um Setor de Atendimento para alunos da EAD.

$\mathrm{Na}$ área de gestão, criou o setor administrativo dos Polos e setor responsável pelo Suporte Técnico de Informática específico para EAD junto ao Núcleo de Tecnologia e Informação.

A gestão do conhecimento na EAD da IES conta com o apoio de uma equipe pedagógica responsável pela estruturação dos recursos metodológicos utilizados, contribuindo com a elaboração das mídias digitais, atenção e respeito às questões legais da propriedade intelectual, direitos autorais e diversidade cultural. Dessa forma, a EAD tem uma equipe direcionada ao uso e atualização das TIC, uma equipe direcionada à produção de materiais impressos e digitais, Coordenador de Curso, o Núcleo Docente Estruturante, professores e tutores presenciais e online 
que atuam na sede.

Além disso, o EAD conta com o suporte de uma estrutura especial de atendimento ao aluno com a finalidade de verificar a assiduidade dos alunos, 0 desenvolvimento das atividades pelos alunos e as dificuldades e problemas específicos dos acadêmicos, incluindo atendimento aos portadores de necessidades especiais. O setor estruturado denomina-se Interação cujos funcionários, com função de agentes interativos, são responsáveis pelo relacionamento aluno e Instituição.

A seguir, apresentamos o cronograma de implantação e o plano de gestão da EAD na IES com o período para realização das ações programadas.

Diagnóstico das Potencialidades (2012); Aprovação dos Conselhos Superiores dos Investimentos em EAD (2012); Treinamento do Pessoal Docente; Treinamento do Pessoal Técnico-Administrativo (2012 a 2016); Implantação de 20\% em EAD nos cursos presenciais (2013); Solicitação do credenciamento em EAD (2013); Implementação dos recursos de TIC (2012); Solicitação de autorização de Cursos em EAD (2013); Credenciamento dos polos de apoio presencial (2013); Treinamento dos tutores online e presenciais (2013 a 2016); Avaliação dos polos (2014); Inicio dos cursos (2014).

Plano de gestão pra a implantação do EAD teve como premissa os seguintes aspectos.

Implantação da Plataforma AVA (2013); Definição do Organograma com EAD (2013); Alteração do Regimento Geral (2013); Nomeação do Coordenador de EAD (2013); Criação do Núcleo de Integração Pedagógica (2013); Criação do Órgão Administrativo dos polos (2013); Criação da Secretaria Setorial da EAD (2014); Desenvolvimento do Sistema de Controle Acadêmico da EAD (2013 a 2014); Investimento na infraestrutura da EAD (2013 a 2016); Preparação dos materiais didáticos e pedagógicos (2013 a 2016); Sistema Administrativo dos polos de apoio presencial (2014); Manutenção e aperfeiçoamento do Sistema de Registro e Controle Acadêmico (2013 a 2016); Aperfeiçoamento da plataforma AVA (2014 a 2016).

Os objetivos do plano de ação foram; estabelecer o design geral de estruturação e funcionamento da coordenadoria de EAD, identificar os elementos estruturantes da 
gestão de processos da coordenadoria de EAD, fixar os referenciais pedagógicos e de tutoria, estabelecer os referenciais para criação e utilização de mídias e tecnologias, produzir os cursos de graduação, extensão, pós-graduação e disciplinas à distância para cursos de graduação presenciais.

O acompanhamento e controle do plano são realizados permanentemente por meio de reuniões, onde os indicadores pedagógicos, a satisfação do cliente interno e externo, além da aplicação adequada de recursos financeiros, são elementos prioritários.

Realizado o acompanhamento e o controle do processo, a avaliação leva em consideração todos os objetivos e elementos envolvidos no processo. Com pesquisa da CPA Comissão Própria de Avaliação. O feedback de todas as ações realizadas deverá merecer destaque especial.

Convém destacar que a significação do EAD na estrutura organizacional da instituição não é um processo concentrado e estagne. Ao ponderar o processo das instituições que investem em EAD notamos uma dinâmica que procura o ajustamento deste método nas composições existentes e um esforço para concentrar as distintas iniciativas em EAD para um objetivo comum, institucional. Trata-se de um processo dinâmico e que recebe influências tanto de políticas internas da instituição quanto de políticas externas.

\section{CONCLUSÃO}

Constitui de fundamental importância a participação como coordenadora do EAD na IES, pois possibilita acompanhar a aplicação das ações realizadas na IES e buscar o aprimoramento de soluções que surgiram neste período. Ampliando o conhecimento na gestão de EAD, unindo a teoria e pratica, explorando os processos de funcionamento de cada setor criado, praticando métodos, normas regras e regimentos.

Busca-se avaliar neste primeiro momento o alinhamento da gestão da IES com a implantação do EAD, com um olhar diferenciado para que constitua presumível analise do que acontece dentro da IES, percebendo o comportamento dos atores envolvidos por meio da observação e do diálogo. Como coordenadora e pesquisadora, procurei observar no primeiro momento e posteriormente dialoguei 
sobre as possíveis ações em relação a determinadas situações.

A implementação do plano de ação, revelou desafios a serem enfrentados e dificuldades devido a complexidade do modelo, como falta de politicas públicas objetivas e claras e diretrizes gerais das instituições para o EAD.

Salienta-se que o cronograma teve seus períodos reestruturados por algumas vezes, devido aos processos de regulação e avaliação do MEC. Postergando algumas ações delineadas. O treinamento de tutores ainda não ocorreu de forma efetiva, até o momento foram realizadas reuniões técnicas para o momento da avaliação dos cursos, criação de um regulamento do sistema tutorial, com o modelo pedagógico adotado pela IES.

O momento político em que o Brasil se encontra atrasou em pelo menos 1 ano o inicio de oferta dos cursos solicitados, ainda pendente a portaria oficial do MEC, mesmo tendo todos os parecer pelas instancias politicas, favoráveis aos cursos e polos.

O ambiente virtual de aprendizagem inicial foi o MOODLE, um software livre de apoio ao aprendizado, escolhido por ser livre, pois a IES já tinha intenção de criar o próprio ambiente de aprendizado, no momento em fase final de testes.

A definição do organograma passou por algumas reestruturações até chegar ao ideal da IES.

A criação dos setores, até o momento, foi o elemento mais acessível dentro do plano de ação sugerido, ocorrendo de forma serena, destacando o recrutamento interno dos interessados e experiente em cada área.

O sistema de gerenciamento acadêmico, já existente na IES, teve algumas configurações criadas e interligadas ao ambiente virtual de aprendizagem e ao sistema administrativo dos polos, possibilitando a interação e colaboração entre os setores e os atores envolvidos.

Apesar de elevado o custo inicial, o investimento é continuo, em estrutura física do EAD, obedecendo a legislação vigente, capital humano e tecnologia.

A preparação de materiais didáticos acontece de forma estruturada, seguindo os referenciais de qualidade do MEC, com o apoio de software preparado para a produção, diagramação, correção, filtro de plagio, além de correções realizadas por equipe multidisciplinar. 
No levantamento do diagnostico final para esta apresentação deparou-se com analise interna e externa.

$\mathrm{Na}$ análise interna pode-se destacar como pontos fortes o apoio e participação efetiva da alta direção, a EAD é vista como objetivo estratégico institucional, orçamento compatível com os projetos, projeto do AVA da própria instituição, construção de bloco exclusivo para o funcionamento da Coordenadoria de EAD, experiência em EAD da Coordenadora contratada em relação à gestão, funcionamento e uso de TIC. E os pontos de oportunidades de inovação e melhoria, dificuldades para operacionalização dos projetos, necessidade de melhoria da rede de tecnologia da informação, incluindo-se computadores, internet e softwares, custos iniciais elevados para implantação da EAD e pouca experiência do corpo docente em EAD.

Análise externa, pode-se evidenciar que os pontos fortes são, o aperfeiçoamento dos softwares livres possibilitando economia, cenário sociopolítico e econômico propício à implementação da EAD, a EAD deixou de ser vista como alternativa secundária, para uma linha de necessidade e o surgimento de novas tecnologias de informação e comunicação. Pontos de oportunidades de inovação e melhoria; crescimento da concorrência, níveis crescentes de exigências governamentais, fazendo com que a EAD perca muito de suas características e potencialidades e a alteração constante da legislação educacional brasileira.

\section{REFERÊNCIAS}

ABED. Censo ead.br: relatório analítico da aprendizagem a distância no Brasil 2010. São Paulo: Pearson Education do Brasil, 2012.

BRASIL. Lei n. 9. 394, 20 de dezembro de 1996, estabelece as diretrizes e bases da educação nacional. Presidência da República. Disponível em: http://portal.mec.gov.br/seed/arquivos/pdf/tvescola/leis/lein9394.pdf. Acesso em: 25 jul. 2014.

BRASIL. Referenciais de qualidade para educação superior a distância. 2007. Disponível em http://portal.mec.gov.br/seed/arquivos/pdf/legislacao/refead1.pdf. Acesso em: 25 jul. 2014.

FERREIRA, I.A. Plano de gestão de EAD. Londrina. 2013.

LUCK, H. Gestão educacional: uma questão paradigmática. Petrópolis: Vozes, 2007. 
SILVA, R.S. Gestão de EAD: educação a distância na era digital. São Paulo: Novatec, 2013.

THIOLLENT, M. Metodologia da pesquisa-ação. São Paulo: Cortez, 2004. 